\title{
A Look into a Professional Learning Community
}

\author{
Nazanin Dehdary \\ University of Exeter, U.K.
}

\begin{abstract}
Professional learning communities are not commonplace in Iran and this is evidenced by the scant literature in this regard. The present study is an attempt to fill the gap in the literature. This study was conducted in the hope of evaluating a professional learning community within an English language institute in Iran to detect the threats to its survival from the viewpoints of some of the teachers and members of the board of studies. The analysis of the data uncovered three major strengths the current PLC enjoys. These plus points are the dynamic work context, management policy, and a nexus of focus communities. There is, however, a consensus among participants that in recent years many teachers have detached themselves from different communities within the institute. The analysis of the data revealed sense of belonging, teacher's view of the profession, infrastructure and flawed dialogue as the major threats.
\end{abstract}

Index Terms - professional learning community (PLC), professional development, teacher education

\section{INTRODUCTION}

There is a widely held belief that the quality of learners' education depends mostly on the quality of teachers (Wood, 2007; Hord, 2009). If teachers are professional, they know how to craft quality education. Teacher quality is given high priority in new approaches to education owing to the fact that student learning and teacher quality are inextricably linked (Shirazi, Bagheri, Sadighi\&Yarmohammadi, 2013). To professionalize their teachers, schools and educational institutions invest large sums of money in providing lots of training, workshops, seminars and courses. However, this top-down approach is flawed since "they have little actual effect on classroom teaching as not much change happens, and if it does, it does not last long" (Farrell, 2015, p7). Transforming teachers into thinkers and inquirers who play an active part in knowledge construction can guarantee quality education. However, this does not take place unless the right supportive atmosphere exists. Darling-Hammond and McLaughlin (as cited in Vescio, Ross \& Adams, 2008) note that "helping teachers rethink practice necessitates professional development that involves teachers in the dual capacities of both teaching and learning and creates new visions of what, when, and how teachers should learn" (p. 80).

Peter Senge's 1990 opinion of turning corporations into learning organizations has had a huge impact on the path many organizations in the world have taken. Senge holds that corporations won't survive unless they are turned into learning organizations which can recognize threats to their survival and seek opportunities for ongoing development. His view has also revolutionized many schools today as transforming a school into a learning community is currently in vogue. However, it takes a huge paradigmatic shift from viewing schools as a bureaucracy to a community (Roberts \& Pruitt, 2008). The vision of employees involved in collaborative learning who are skilled at creating knowledge can well depict a professional learning community (PLC). In such a community, team work, collaborative learning, sustained reflection, and sharing professional practices are the foundations (Roberts \& Pruitt, 2008).

I believe that if we teachers do not find the right supportive atmosphere, our teaching concerns and questions usually get lost in the everyday ebb and flow of life. We do the same practices again and again until they look like common sense. In order not to get into the trap of routines, we need to build a quality professional learning community and if we have one we need to evaluate it, see its threats, look into its weaknesses and strengths, and make an endeavour to turn it into an opportunity for both teachers and students' growth. Professional learning communities need maintenance and care, and if their voices are not heard and the threats to their survival and development are not taken seriously, they might soon become extinct.

My own experience of professional development began in a small learning community my colleagues and I had built within a large institution of nearly 120 teachers. Our community was founded on teacher dialog and collective critical reflection. The supportive and non-threatening environment provided me and my colleagues with the chance to share all the questions that occupied our minds and the teaching practices that we were hesitant about. Having the privilege of unbiased colleagues and rich dialog increased my awareness, boosted my confidence, and helped me design more effective teaching practices. Our community was a spontaneous one which in time strengthened and developed. However, in recent years this community is suffering, as evidenced by member attrition and cancellation of a number of learning groups. This study aims to look into the climate of this professional learning community in Iran by investigating the viewpoints of the teachers and members of the board of study about their PLC and looking into the challenges this community is dealing with. 
This study was carried out in the summer of 2016 in Iran where English is taught as a foreign language by mostly Iranian bilingual teachers. In recent years, there has been a dramatic rise in the number English language institutes all across the country due to the inadequacy of English programs in schools. A bachelor's degree in teaching English or a relevant field with a very good level of English language proficiency is the minimum requirement for recruitment in these institutes. There are usually initial training programs tailored according to the priorities and objectives of the school. They might then be followed by in-service development programs depending on both the vision and budget of the institute.

In the female branch of the institute where this study was carried out, there are around 80 female bilingual teachers teaching kids, young adults, and adults in 5 different branches. The pre-service training program consists of 40 hours of both theoretical and practical language teaching issues where teachers get familiar with the fundamentals of English language teaching in general and the current teaching methodology of the institute in particular. Teachers are then provided with the booklets of methodology specific to the institute, textbooks and the syllabus specifying the number of lessons they are required to cover before the midterm and final exams. Next, based on the level they are assigned, teachers are grouped into teams with coaches to guide them. The coaches devise different activities for them to perform ranging from weekly meetings to self, peer, and group observations. Apart from that, some teachers, particularly the newly-recruited ones, voluntarily team up, write lesson plans together and request to have peer observations. They turn team work into a habit and pursue their self-development through small communities they willingly join. There are also teams planned by the authorities for more experienced and senior teachers. Even though some teachers express genuine interest in partaking in these communities, there are other teachers who see it as an additional burden, are usually dragged in to attend and would prefer to teach behind closed doors.

This institute is a private institute supervised by the Iranian Ministry of Education and run by a board of managers who are the owners of the institute and should approve all the educational decisions made by the board of studies. Teacher recruitment, teacher initial training and professional development, material selection, and level assignment to the teachers are among the major responsibilities of the board of studies.

\section{REVIEW OF THE LITERATURE}

This interpretive study seeks to develop a more transparent image of a professional learning community in a language institute in Iran. This section reviews the relevant literature related to the nature, building blocks, and benefits of a PLC. This section concludes with a brief look inside research on teacher development in Iran.

\section{A. What Is a PLC?}

Looking through a sociocultural lens, learning is a social act and individuals are active participants constructing their own learning community (Mitchel, Miles \& Marsden, 2013). To put it another way, the environment is responsible for nurturing and scaffolding learning. Contrary to the followers of cognitive theorists who place the focus on individual cognition and hold that learning is a mediated process between the stimulus and the response, the sociocultural theorists' main concern is the individual's surroundings. To them, learning is the by-product of collaboration between individuals.

PLC also considers learning a social rather than an individual act. As the term Professional learning community suggests learning is not an individual affair to take place in a vacuum but happens in a community of professionals. This community; however, is more than a simple gathering of individuals. It is goal oriented, meaningful and calls upon teachers' professional spirit and commitment to not only their own learning but also to that of their students' (Hord, 2009).

The idea of professional learning community originated from the notion of learning organizations (Senge, 1990). The differences, however, in the ends and means between a learning organization and a school have made educators consider schools a learning community rather than a learning organization. In a learning organization, the ends are organizational growth and productivity through learning. In other words, learning is a tool. In contrast, the end in a learning community is people growth which takes place through ongoing discourse and communication in the community (Mitchel \&Stackney, 2001). Stoll and Louis (2007) posit that a universal definition of professional learning community does not exist but one can certainly be found when groups of teachers discuss and critically reflect on their teaching practices in an ongoing and collaborative way with the intention of promoting growth. Despite the fact that there is no definite definition for a learning community, Mitchel and Stackney (2001) point out that all learning communities have shared vision, communication, risk taking, trust, and mutual respect in common.

Buysse, Sparkman and Wesley (2003) state that a learning community is grounded on two major assumptions. First, knowledge in a community is constructed through critical reflection of the teachers on their day-to-day experiences. Second,teachers' knowledge enhancement improves students' learning. Stoll and Louis (2007) adds that a PLC does not centre around individual teacher's learning but strives to hone collective knowledge within a cohesive group that not only impacts upon the professional lives of school teachers and leaders but also permeates the lives of students. In Pirtle and Tobia's (2014) words PLC is a "powerful infrastructure" where teachers learn how to act more effectively to enhance learning in their students. 
Apart from the positive impact of PLCs on students' achievement, Dufour and Dufour (2010) consider PLCs as a sine qua non for the $21^{\text {st }}$ century success and add that educators within a school need to collaboratively clarify the skills required for success in this new century and the best practices they can employ to help individual students acquire these skills. In addition, to deal with the constantly-changing world occurred by globalization, learning requires a collective effort and should be done collaboratively rather than be left to individuals (Stoll et. al., 2006). Little (2001) claims that instructional improvement and school reform are the fruits of a PLC. Fullan also supports this claim by mentioning that reform in educational institutions can take place through developing PLCs (as cited in Dufour\&Dufour, 2010).

\section{B. The Building Blocks of a PLC}

\section{- Shared mission and values}

A clear sense of mission and shared values are indispensable to a PLC. A shared mission and vision take place when walls of isolation are broken down and people work on goal-oriented teams and strive to "establish specific, measurable, attainable, results-oriented, time-bound (SMART)" goals pertaining to student learning and try hard to achieve them (Dufour\&Dufour, 2010). To DuFour (2003) the mission "is not simply to ensure that students are taught but to ensure that they learn. This simple shift—from a focus on teaching to a focus on learning — has profound implications" (para 5). Dufour and Dufour (2010) posit that having a PLC requires working in collaboration rather than in isolation and collective inquiry about students' learning issues within their context which can eventually contribute to shared knowledge and, to Stoll and Louis (2007), a "common understanding of concepts and practices" (P. 3).

\section{- Ongoing constructive dialogue}

The quality of learning among teachers lies in the climate of the learning community. In other words, the social aspect of the community plays a determining role. Stoll and Louis (2007) maintain that collaboration contributes to desirable process. Teachers need genuine dialog to open up, exchange ideas, learn collectively, maintain relationships and construct a community. However, due to the complexity of the mentioned layers, developing a professional learning community is by no means easy. In a learning community, the social aspect of learning determines the cognitive climate which means that learning is a direct result of negotiation among the individuals in a learning community. Issacs (1999) states that maintaining a dialog requires the skills of listening, respecting, suspecting, and voicing. These skills set the groundwork for disclosure and criticality that characterize a learning community. Easton (2015) recognizes dialog as a key skill and mentions that "without the skill of dialog, professional learning communities may become dysfunctional" (para. 20). He also adds that "it must be learned, consciously practiced and purposefully employed when it is important to surface everyone's ideas" (para. 23).

\section{- Collective reflection}

In an exhaustive study on factors determining student learning, Hattie (2008 as cited in Dufour\&Dufour, 2010) considers collective reflection to be a leading factor. He adds that reflection in isolation can barely promote growth. Moreover, when collective reflection is accompanied by expertise and evidence of effective student result in their context, reflection has been proven to be more effective and teachers are better prepared to cope with the challenges within their context (Dufour\&Dufour, 2010). Learning within a PLC requires deconstruction of knowledge via reflection followed by reconstruction and co-construction of knowledge via collaboration with peers (Mitchel \&Sackney, 2001).

\section{- Atmosphere of trust}

Tschannen-Moran (2014, p. 17) defines trust as "one's willingness to be vulnerable to another based on the confidence that the other is benevolent, honest, open, reliable, and competent." She also adds that it is the duty of the school leaders to build a trusting and non-judgmental atmosphere in which the teachers willingly want to be involved in the kind of conversations that make them deeply reflect on their teaching practices and eventually help PLCs to thrive. Hord (2009) calls trust an imperative to a PLC and holds that for a PLC to be constructive, learning needs to take place in a social setting of collegiality and authenticity.

\section{- Supportive leadership}

There is no doubt that supportive leadership can provide the scaffold for developing and maintaining a PLC. Supportive leadership not only contributes to the sustenance of a PLC but also provides the safety a PLC should be built on. Hord (2009) mentions the two factors of time and place and adds that it is the school leader's responsibility to adjust the school schedule in a way that teachers can easily access time for their PLC and should ensure a place that can accommodate the whole community.

\section{PLC Effects}

Mclaughlin and Talbert (2006) state that "deprivatized" teaching provides the foundation for teachers to develop not only common understanding but also shared language about their practices. In addition, shared vision and collective learning leads to collective responsibility for their students and together the whole experience generates collective growth. They go on to note that administrators can also benefit from the PLC as they can reinforce norms and standards of their expected teaching practices. In A review of research on the impact of professional learning communities on teaching and student learning, Vescio, Ross and Adams (2008) posit that evidence from extensive research suggests a positive correlation between PLCs, improved teaching practice, and student achievement. Furthermore, the intense 
focus on student learning, teachers' perpetual learning, teacher collaboration and teacher improved authority can help promote the school culture.

\section{Teacher Development in Iran}

On the way towards professionalizing teachers, schools and institutes in Iran provide in-service programs to both update and enhance their teachers' expertise (Razi\&Kargar, 2014). However, these in-service programs usually conclude with certificates that can merely help teachers collect credits for their appraisal and promotion purposes (Razi\&Kargar, 2014). According to Shirazi et al (2013), teacher education in Iran is barely satisfactory. The traditional one-size-fits-all is still the most dominant approach to teacher education. Shirazi et al describe the dominant teacher training as episodic and fragmented with its focus mainly on generic issues. The results of a study conducted by Birjandi and DerakhshanHesari (2010) revealed that the inadequacy of training programs in Iran cannot cater to the teachers' needs and are far from satisfactory. Professional learning communities are not commonplace in Iran and this is evidenced by the scant literature in this regard. The present study is an attempt to fill the gap in the literature of PLCs in Iran. In addition, it can mark the beginning of research on PLCs in Iranian educational contexts.

\section{RESEARCH DESIGN}

\section{A. Research Questions}

In order to gain a more transparent image of the PLC the following are the questions this study intends to address:

1. What are the strengths of their PLC from the viewpoints of teachers and members of the board of study?

2. What are the threats to the PLC from the viewpoints of teachers and members of the board of study?

\section{B. Research Framework}

This research project is informed by the interpretive paradigm as it strives to merely describe the status quo of a PLC from the perspectives of the main beneficiaries i.e. teachers and members of the board of study. To improve the professional learning community in the institute under the study, I believe, a clear picture of the reality of the PLC should be obtained. This image can shed some light on how distant the current PLC is from the objectives and how large the gap is. To this end, I have looked into the strengths and weaknesses of a PLC adopting an interpretive framework.

Interpretivism which arose out of the philosophy of Edmund Husserl's phenomenology and Wilhelm Dilthey's and other German philosophers' hermeneutics refers to many variations of approach to social research such as "relativism, phenomenology, hermeneutics, idealism, symbolic interactionism, and constructionism" (Grix, 2004). To interpretivists, reality is subjective and socially constructed and the world is interpreted from the perspective of its "social actors" (Pring, 2000, p. 98). According to Cohen et al (2011), social reality in the interpretive paradigm is understood and explained through the lenses of the participants. By the same token the proponents of this paradigm hold that "research can never be objectively observed from the outside rather it must be observed from inside through the direct experience of the people" (Mack, 2010, p. 8). Thus, the researcher within interpretivism is not detached from the research as interpretivists hold a subjective predisposition towards the discovery of reality. Interpretivists appreciate and respect the differences among people's interpretations and make an endeavour to discover the subjective interpretation of social reality in an inductive manner. However, one of the major limitations of this framework is that research findings within this paradigm are not generalizable but can be transferable if they fit into similar contexts.

\section{Data Collection Method}

I was going to use both questionnaires and interviews to collect data. However, due to the contextual constraints and problems concerning finding the right number of participants, I opted for interviews. The kind of interview I selected was group interviews rather than one-to-one interviews as the diversity of perceptions in a group interview and its dynamic nature can develop discussions which can, in turn, assist the researcher in obtaining deeper data and eventually making a better assessment of the interviewees' beliefs. Compared to one-to-one interviews, the data obtained from group interviews are deeper and richer (Thomas, as cited in Rabiee, 2004). Cohen et al (2011) also mentions that group interviews naturally create a wide range of responses compared to individual interviews. Krueger (2014) posits that a group exhibits a synergy which cannot be found in one-to-one interviews. He adds that group interviews are used when the range of opinions and beliefs about a particular issue are sought. In addition, the nature of the group interview can both cross-check and complement the opinions providing a more reliable and thorough picture (Arksey\& Knight, as cited in Cohen et al, 2011). For the above-mentioned reasons, I selected group interviews in order togain a more transparent image of the situation from the view points of the participants.

\section{Participants}

The number of people who were invited to partake in this study totalled 8 . The participants were put into two groups in accordance with their positions in the institute. Group A was comprised of 5 female teachers in the 29-36 age range and teaching experience of 8.5 years on average. Teachers in group B, on the other hand, are members of the board of studies and make pivotal decisions regarding teacher professional development and initial teacher training. The teachers 
in this group were one male and two female teachers with the age range of 37-58 and had been in their positions for around 12 years. The participants of the study were selected purposefully rather than randomly because their experience of working as both teacher and professional development planner assisted me in gaining a better picture of the professional community in the institute from two different perspectives.

\section{E. Procedures}

The interview questions (Appendix A) were designed in relevance to the objective of the study and were prepared ahead of time. The structure of the interview, however, allowed me to ask spontaneous questions to better delve into the matter at hand. To ensure that the questions were the right questions and could serve the purpose, I conducted a pilot interview using the draft questionnaire with one of my former colleagues who was aware of the objective of the study a few days prior to the interviews. The pilot interview helped me delete some ambiguous questions and gave me a chance to ensure that my questions were not prejudicial, double-barrelled, or leading. During the pilot, I also checked the chronological order of my questions to ensure their smooth transition. After the pilot interview, I came up with a shorter list which I was more confident both about the quality of the questions and their order.

The participants' asymmetry of power was the major factor to categorize them into two groups as some were teachers and some were members of the board of study. Due to their grouping and homogeneity of their background, the discussion was developed with ease. In addition, the rapport among the group members let them feel safe to open up and express their true opinions freely. Disagreement was witnessed a few times which was a good sign that the participants were not hesitant to express their true opinions. A few cases of misunderstandings were cleared by the members through additional questions they posed and explanations they provided. The above mentioned items all added to the accuracy and reliability of the data.

Each interview started with a short briefing in which I clarified the main objective of the interview and put the interviewees at ease by mentioning the ethics I am bound to follow. I defined the concept of professional learning community briefly and a few questions were asked regarding the concept prior to the interview. I kept all my questions short and to the point and for the sake of reliability the same questions were asked a second time using different wording. Furthermore, the meanings of the interviewees' statements were clarified by providing interpretations of their answers verbally. Efforts were made to ensure everyone responded to the questions and each participant was given enough time to speak. Their responses were natural as it was a discussion and there was no turn taking as I believe it can damage the nature of a discussion. The teacher interview (group A) took 1 hour and 12 minutes and the interview of the members of the board of study (group B) lasted 48 minutes. The interview questions were written in English, but since I speak the participants' mother tongue, all the interviews were conducted in Persian in order to help the participants to articulate what they intended to express with ease. All interviews were conducted in quiet places. The interviews were recorded, transcribed in Persian and color-coded in order to derive the emerging themes and analyse the data. (A sample has been provided in Appendix B.)

\section{F. Data Analysis}

Before transcribing the interviews, I listened to all interviews to find connections between the different sections and also their ties with the literature. After that I transcribed all the recorded interviews in Persian and read them all thoroughly. The interview data revealed the major categories themselves. The data was coded based on the emerging themes and sub themes. To conduct data analysis, I followed Wolcott's (1994) suggestions of data descriptions, data analysis, and data interpretation. I did my best to be faithful to the teachers' viewpoints and avoid biased interpretation of the data. Data analysis suggested a number of themes which have been categorized into the strengths and weaknesses of the community.

\section{G. Ethical Considerations}

In keeping with the University of Exeter ethics guidelines, all the necessary ethical procedures were followed. The participants were informed fully of the purpose of the research and a written information sheet explaining the details, the purpose of the research and information regarding their anonymity, confidentiality and the fact that their participation is voluntary and they have the right to withdraw any time during the research accompanied the consent form. In addition, the institute's permission was required for all the interviews after the details and the purpose of the study were explained to the managing director of the institute.

\section{H. Limitation of the Study}

There is an extensive research base on the benefits of a professional learning community. Nevertheless, little has been said about the challenges, threats and the solutions. This study can contribute to the knowledge and better understanding of a PLC especially in Iran where there is almost no literature on professional learning communities. It can also provide a lesson for other professional learning communities with similar structures. This study is limited owing to the fact that it is a small scale qualitative study with a limited number of participants. Therefore, the results are not generalizable and representative of a particular population. They can, however, be transferrable to similar contexts.

\section{FINDINGS}


This section aims to clarify the results of the data analysis which has been categorized based on the research questions into the two main themes of strengths of the PLC and the threats to the PLC. Some extracts from the interviews reflecting each theme have been selected. What follows is an explanation of each theme. For ease of matching the extracts with the two groups, the pseudonyms of the participants from each group are as follows:

Group A: Nina, Elly, Rim, Mariam, and Sara

Group B: Fanya, Sally, and Eric

\section{A. Strengths}

Dynamic work context, management policy, and a nexus of focus communities are among the themes arising out of the interviews concerning the positive attributes of the community.

\section{- Dynamic work context}

All the interviewed participants are of the opinion that their community is a dynamic one encouraging ever yone to be up-to-date. Nina says, "This institute naturally pushes you forward to learn". She compares this institute with her previous work places and believes that the current institute has altered her outlook on teaching. She adds, "When I entered this institute, I felt that the teachers here were a lot more professional than me. This made me want to learn more. I bought some books on methodology and even decided to do my MA in teaching". Elly believes that the diversity of the teachers in terms of age, experience, academic knowledge, and personalities has added to the dynamic nature of this community. Rima is of the opinion that to survive in a dynamic environment, one has no way but to stay dynamic as an individual". Fanya shares her personal experience and explains, "When I entered this institute, I didn't have formal education in teaching. Taking part in different communities within the institute inspired me to gain expert knowledge and the confidence that have enabled me now to discuss issues in the field with the ones with formal education". She also adds, "I do consider this place a learning community".

\section{- Management Policy}

"We have always been asked to discover new talents", says one of the participants from group B. She adds that the general policy in the institute is to look out for the teachers with talents and provide opportunities to nurture them. She concludes that the community today is grounded on the philosophy of talent discovery". In this regard, Rima says, "contrary to other institutes, we were seen here. We've been told what we are good at and we have made it bolder in our teaching". Eric, calls this community a strong learning one despite all its challenges and mentions and believes that this community is one-of-a-kind in Iran. With regard to the expectations existing in the institute, Rima states that if the people in charge were not demanding, the teachers might not feel the need to work hard and put in the necessary effort. Elly holds that the high expectations of the institute can motivate the teachers to work harder in order to shine. Eric confirms this point by saying that even the most indifferent teachers have also grown due to the general expectations in the institute. Their growth is not substantial but adequate to put them on the right track. Fanya also adds, "Our weakest teachers have even had some development, and this does not take place everywhere".

\section{- A nexus of focus communities}

Due to the large number of teachers, smaller communities each with a particular focus geared toward the same vision have been created for teachers to join. It is expected that joining these communities can help teachers meet their professional needs of different kinds. Teachers across all levels are always encouraged to get involved in these learning groups; however, joining some such as the learning communities for the new teachers is mandatory. Rima calls communities for the novice teachers the best and biggest change which has ever taken place at the institute. She believes that this community has broken the ice and replaced resistance with flexibility. Mariam, one of the participants from group A, emphasizes how helpful observing classes of the senior members of the community as one of the followup tasks assigned in her group has been. She, then, shares a personal experience of her first term working at the institute and mentions, "while observing a model class, I told myself ...aha... this is the standard they expect from me". Sara, another participant from group A, explains, "Peer observation within the communities has brought about keen competition pushing you to do something for your own professional growth". Elly says that she envies the new teachers and believes that the kind of service they receive cannot be found anywhere else in town. In this regard, Dufour and Dufour (2010) mention that a successful learning community is a facilitator in the hiring process as it provides a smooth transition for the newly-hired teachers and never lets the traditional swim-or-sink approach happen again.

It is evident that collective learning takes place more easily in smaller communities than in larger ones. Fanya also talks about the professional dialogue in these groups and mentions how much these dialogues have promoted professional growth and learning. There is a consensus among the participants that the existence of several communities within one large community has also added to the dynamic nature of the PLC. They add that collective learning and professional dialog have contributed to both the bond among teachers and their professional development.

\section{B. Threats}

There is a consensus among participants that in recent years many teachers have detached themselves from different communities within the institute and there has been a sharp decrease in the number of teachers who willingly want to join. Sally from group B mentions that there isn't enough motivation for all to take part in learning communities and those who have stayed are intrinsically motivated. She further continues, "We haven't been able to convince everyone to join". Another participant from group B believes that the institute once created a great PLC; however, their recent 
policies have damaged this community. When asked why they think the learning communities are suffering from teacher attrition the following themes emerged:

\section{- Teacher's sense of belonging}

One of the participants from group B is of the opinion that the institute has not been able to create a sense of belonging in the teachers. She further explains that if the management does not have a long-term policy, long-term planning for teachers never happens and as a result, sense of belonging is never built in teachers. Another teacher from the aforementioned group explains that adequate acknowledgement does not exist and this, undoubtedly, ruins one's sense of belonging. One's job will not be considered his/her top priority any longer. Despite the fact that there isn't much systematic research on teachers' sense of belonging, there should be a positive correlation among teachers' sense of belonging, motivation, and job satisfaction (Skaalvik\&Skaalvik, 2011).

\section{- Teacher's view of the profession}

"Some of the teachers working here, especially female teachers do not see teaching as their career. As their pastime, they take a few classes", says Fanya. The participants from group B explain that male teachers who are mostly the major breadwinners of their families view teaching as a source of income. Instead of spending time in learning communities, they can take a couple more classes and make more money. Rima mentions limitations of different kinds such as time, personality, and teaching limitations and explains that these limitations have prevented some teachers to get their promotions. She adds that this has created a sort of enmity between those who have managed to get promotions and those, especially the veterans, who have failed. She believes the veterans do not hold a professional view and blame others for their faults.

\section{- Infrastructure}

Two of the teachers from group A express their concerns about teacher morale and the "so what?" question that occupies their minds. Participants from group A point out that teachers in this institute are recently under a lot of pressure to reach the standard. Their putting a lot of effort may in the long run backfire and makes them reach the "so what?" threshold. Sally confirms this point by saying, "There's no gain”. Other participants from group B explain that there are no perks and continue that their professional growth can hardly be turned into a pay raise. Eric quotes from the teachers working in the institute, "they want me as long as I can work like a tractor. As soon as I lose steam, they say goodbye".

In a study on factors contributing to Iranian EFL teachers' emotional exhaustion, Mahmoudi-Shahrebabaki (2015) identifies income as one of the major stressors for teachers making them consider quitting. He explains that teachers explicitly state that their efforts for professional development do not influence their income. He also called the income factor as the number one reason for teachers' frustration, lack of interest or in a word "compassion fatigue" (Chang , as cited in Mahmoudi-Shahrebabaki , 2015).

Teachers in group B hold that the degradation of their learning community is due to lack of transparency and job security. They hold that teachers' being given two-month contracts have greatly disillusioned the teachers about their profession. Consequently, teachers cannot visualize a future in the institute as they believe they are more assumed as short-term teachers and that is the reason teachers are not invested in. Fanya complains about the dearth of transparency in the institute's promotion and pay raise policies. "Teachers should be clear on what they gain besides professional growth", mentions Fanya. Sally confirms this point by mentioning that the institute needs to have a much stronger organizational plan. She adds that at the moment it is more like a "come what may" policy". Most of the participants believe that frustration has led to a sort of non-cooperation and disobedience mostly witnessed among the senior teachers.

Cynicism among veterans might prompt resistance to PLCs as they might refuse to take part in the meetings of PLC. Evans (2001) states that "teacher-centered" leaders build the right work context for their teachers as they show as much care and interest in the individual teacher's well-being and welfare as child-centered teachers towards their students. She continues that in teacher-centered leadership approaches, the work context is grounded in tolerance, cooperation, compromise and consideration for others. In such an approach, leaders are also expected to explicitly clarify their ways of operating or in Evan's words "lay their cards on the table and allow teachers to see a hand they could expect to be dealt if they accepted a specific post" (p.304). In other words, she emphasizes the importance of transparency and explains that in such a work-context, teachers' morale is higher and teachers exhibit a more positive job-related attitude.

\section{- Flawed dialogue}

Sara mentions fear and explains that fear of judgement and losing face deters community members from opening up, sharing their stories and asking their questions with ease. She believes that the atmosphere is not always teacherfriendly. Sally confirms this point by saying, "interaction among members has faded away. Managers should know that dialogue is the basis of each community". It's very unlikely that teachers partake in peer observation, feedback, and discussion if they do not feel safe (Stoll, et al, 2006).

Through reflection, teachers assess their practices to ensure they are in line with their beliefs and values. According to Grey (2011), engaging in professional dialogue helps create a professional learning environment in which teachers reflect on authentic situations and can be exposed to new ideas and perspectives. Sharing personal stories and thoughts can nevertheless promote anxiety (Fook\&Askelund, as cited in Grey, 2011). Grey further mentions that a trusting context can guarantee teachers' feeling of safety in sharing their personal stories and exchanging constructive feedback. 
In addition, deep reflection which is considered to be "the cornerstone of a true PLC" does not take place unless the atmosphere is supportive and nonjudgmental (Pirtle\&Tobia, 2014, P. 4).

\section{DISCUSSION AND CONCLUSION}

There is no denying the fact that professional learning community is embedded in today's world of education (Stoll \& Louis, 2007) as Schomker(as cited in Dufour\&Dufour, 2010) states we are approaching a milestone in the history of education as in the future "the absence of a strong PLC in a school is an embarrassment" (p. 431). Building a PLC requires alterations to the way schools operate and how professionals try to promote success for every single student (Talbert, 2010). PLC construction, however, is a formidable challenge which is worth the effort.

This study was conducted in the hope of evaluating a professional learning community within an English language institute to detect the threats to its survival from the viewpoints of some of the teachers and the members of the board of studies. I am of the opinion that assessment in schools should not be mainly directed to student evaluation. It is time to assess PLCs as well. After establishing one, a learning community needs maintenance. Otherwise, it might simply wither. In addition to challenges, the strengths of a PLC need to be recognized and fostered to help the ones in charge to better cope with its threats.

All participants from both groups confirmed that their community is a PLC after features of a professional learning community were briefly discussed. The analysis of the data uncovered three major strengths the current PLC enjoys. The dynamic work context, management policy, and a nexus of focus communities are the plus points. The word dynamic was the most recurrent word which the members used with pride to describe their community. They all held that this major characteristic is a driving force in bringing about change in several aspects of their career structure including their professional outlooks and plans. The dynamic nature of this context cannot have been created by accident. Conscious and deliberate attempts keep it vigorous. Moreover, talent discovery helps to promote its dynamic nature. The philosophy of nurturing professionals from within the institute suggests that teachers are viewed more as its capital. When teachers feel that they are seen and are not left in the margin, they want to stay, develop, and be involved in the current professional evolution. The existence of a nexus of focus communities is another advantage mentioned by the participants. One single learning community cannot take place within a large institute with a large number of teachers. Instead, it has been broken down into smaller communities. Having smaller communities, which share the same vision and mission, can create a better cohesion among the members and give these communities better chances of survival. The diversity among the teachers in terms of experience and knowledge can help teachers to be involved in vertical dialogues which they find rich and thought-provoking. The dialogues especially the ones in the communities of novice teachers are based on their authentic practices as they are engaged in peer and group observation in which one teacher or groups of teachers observe either a veteran teacher or one of the fellow members of the group. In the former observation, standards can be both set and seen and the latter can create competition among teachers.

Participants from both groups, however, held that except for the community of the newly-hired teachers which is mandatory, their PLC has recently deteriorated. They consider teacher attrition as the main contributing factor. When asked why they think their communities are suffering from attrition, the analysis of the data revealed sense of belonging, teacher's view of the profession, infrastructure and flawed dialogue as the major reasons. Sense of belonging has been shattered as teachers cannot see themselves in the institute long-term policies. Obviously, this feeling leads to more detachment as teachers begin to think of plan B and other alternatives outside the institute. Although some teachers in group A were satisfied with the institute's recognition of their talents, the participants in Group B complained about a dearth of recognition. It seems as if talent discovery can serve as recognition temporarily and the ones in charge should also consider other ways of appreciation. Some of the teachers are said to be indifferent towards the institute as they do not consider teaching as their career. They just teach to fill their free time. Others see teaching as merely a source of income and never want to sell their hours for nothing when they can make money. Teachers' explicit defiance has its roots in their feelings towards the institute as they see no transparency, job security and monetary value in their participation. These have caused the so what question. In addition, the two-and-a-half-month contract can provoke cynicism as I believe the length of the contact itself is contrary to the view of professionalism. Anxiety resulting from an unsafe dialogue can terminate a community as the major tool that can unite the members and help the community to mature is interaction. If members do not feel safe, they either resort to avoidance when they are present or prefer to not attend.

There is no doubt that PLC should be added to the recipe of teacher development. This study, however suggests that establishing a PLC does not suffice and its sustenance requires regular maintenance due to its vulnerability. Its challenges and threats to its survival should be identified regularly and action should be taken to restrict its threats and keep it fresh and vigorous. Teachers are the major building blocks of a community and motivation and a sense of purpose is its cohesive force. Taking care of a PLC means taking care of the teachers and providing the infrastructure that gives teachers adequate motivation to join and a reason to stay. Stoll and Louis (2007) maintain that a professional learning community can survive providing that the needs of the humans are taken into consideration. They also add that due attention should be paid to not only the culture of PLC but also the priorities of the people of the community. Setbacks, conflicts, and challenges are inevitable, but what matters is taking the challenges seriously and making an effort to resolve them. In fact, Dufour and Dufour (2010) believe that educators' responses to the setbacks and mistakes 
can contribute to either success or failure of a PLC. This study once again emphasizes strong ties between the PLC and leadership support. The ones in charge should provide the condition in a way that joining a PLC makes sense.

\section{APPENDIX A}

\section{Interview Questions}

1. Is your community a professional learning community? Why?

2. What are the plus points of your learning community?

3. What are the challenges and the threats to your community?

4. What causes these challenges and threats?

5 . How do you see the dialogue in your community?

6. How has this community affected your professional life?

\section{APPENDIX B}

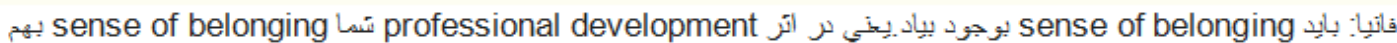

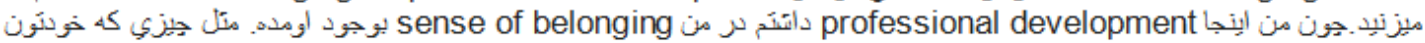

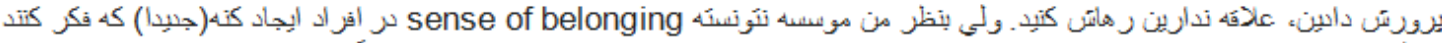

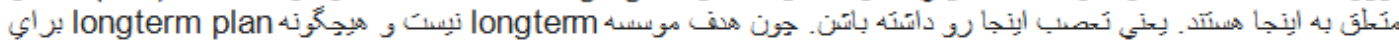

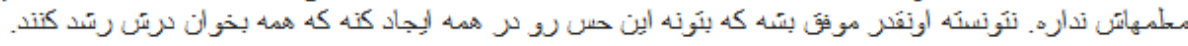

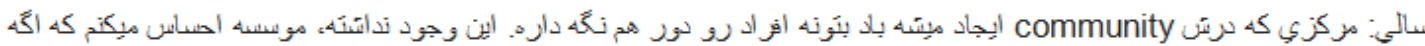

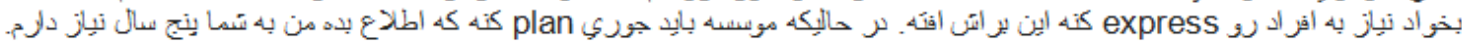

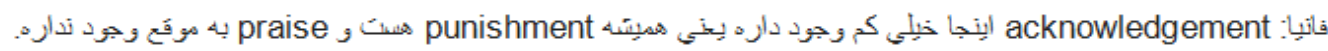

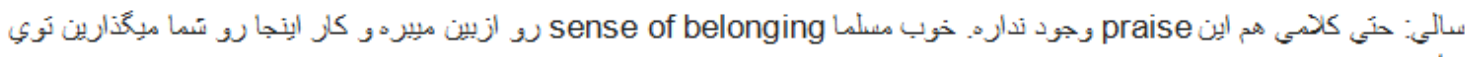

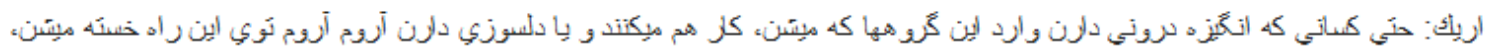

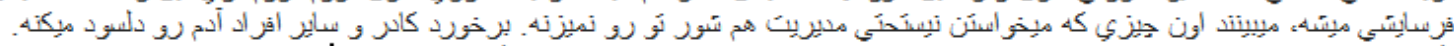

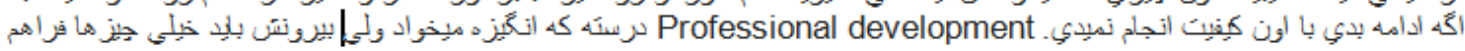

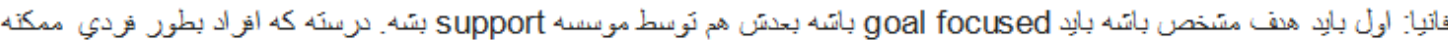

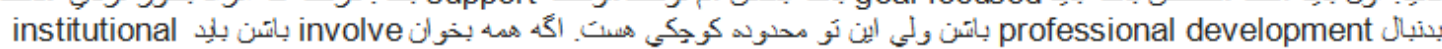

$$
\begin{aligned}
& \text { Support }
\end{aligned}
$$

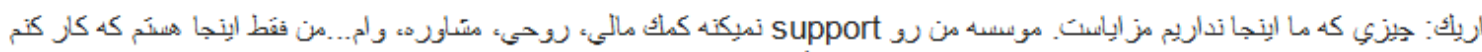

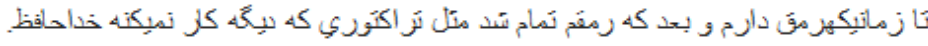

Fanya: Sense of belonging should be created and this sense can be built through professional development. The sense of belonging created in me was due to the fact that I had professional development here. It's like something you have nurtured. You don't like to leave it. I believe the institute has [recently] not been able to create and develop this sense and make the teachers believe that they belong to the institute and make them have strong feelings about it. It's because of the fact that the goal of the institute is not long-term and it does not have any long -term plans for the teachers. It hasn't managed to create this sense in the teachers to make them want to stay and develop here.

Sally: when a community is created, the institute should be able to retain the people. This has not been here. I think, the people in charge never express their needs to the individuals. They think it is below them. The institute should have a sort of planning that expresses its need. For example they should say we need you for five years.

Fanya: There is little acknowledgement here. There is always punishment but there is no timely praise.

Sally: Even verbal praise does not exist, so obviously sense of belonging does not develop and your work here is not your top priority any longer.

Eric: Even those with intrinsic motivation, gradually get demotivated and feel burnout for they see that it is not what they want. Even the directors are not as concerned as you are about the institute. The attitude of the staff disappoints you. If you continue working, it won't be with the same quality. It's true that professional development requires intrinsic motivation, but lots of things should be provided outside.

Fanya: The goal should be identified. It should be goal-focused. It also needs to be supported by the institute. It's true that individuals might want to follow professional development on their own, but it is limited. If you want to involve everyone, there needs to be institutional support. 
Eric: What we don't have here is perks. The institute does not support us..financially, spiritually, no consultations for teachers, no loans. I'm just here to work as long as I can, and the time I run out of steam...just like a tractor...they will say goodbye.

\section{REFERENCES}

[1] Birjandi, P., \& DerakhshanHesari, A. (2010). teachers' perceptions of the present and optimum status of the inservice EFL teacher preparation programs. English language Teaching, 3(4), 47-57.

[2] Buysse, V., Sparkman, K. L., \& Wesley, P. W. (2003). Communities of practice: Connecting what we know with what we do. Exceptional children, 69(3), 263-277.

[3] Cohen, L., Manion, L., \& Morrison, K. (2011). Research methods in education (7th Edition). London: Routledge.

[4] DuFour, R. (2003). Building a professional learning community. School Administrator, 60(5), 13-18.

[5] DuFour, R. \& DuFour, R. (2010). The role of professional learning communities in advancing 21st century skills. In J. Bellanca \& R. Brandt. (Eds.). 21st century skills: Rethinking how students learn, 77- 95. Bloomington, IN: Solution Tree Press.

[6] Easton, L. B. (2015). The 5 Habits of Effective PLCs. Journal of Staff Development, 36(6), 24-34.

[7] Evans, L. (2001). Delving Deeper into Morale, Job Satisfaction and Motivation among Education Professionals Re-examining the Leadership Dimension. Educational Management \& Administration, 29(3), 291-306.

[8] Farrell, T. S. (2015). Reflective language teaching: From research to practice. New York: Bloomsbury Publishing.

[9] Grey, A. (2011). Professional dialogue as professional learning. New Zealand Journal of Teachers' Work, 8(1), 21-32.

[10] Grix, J. (2004). The foundations of research. London: Palgrave Macmillan.

[11] Hord, S. M. (2009). Professional Learning Communities: Educators Work Together toward a Shared Purpose. Journal of Staff Development, 30(1), 40-43.

[12] Issacs, W. (1999). Dialogue and the art of thinking together. New York: Doubleday.

[13] Krueger, R. A., \& Casey, M. A. (2014). Focus groups: A practical guide for applied research. Thousand Oaks California: Sage publications.

[14] Kvale, S. (1996). Interviews: An Introduction to Qualitative Research Interviewing. Thousand Oaks California: Sage Publications.

[15] Mack, L. (2010). The philosophical underpinnings of educational research. Polyglossia, 19, 1-11.

[16] Mahmoodi-Shahrebabaki, M. (2015). Detecting agents of emotional exhaustion among Iranian language teachers within the framework of attribution theory. Education Sciences \& Psychology, 34(2).45-61.

[17] McLaughlin, M. W., \& Talbert, J. E. (2006). Building school-based teacher learning communities: Professional strategies to improve student achievement (Vol. 45). New York: Teachers College Press.

[18] Mitchell, C., \&Sackney, L. (2001).Building capacity for a learning community. Canadian Journal of Educational Administration and Policy, 19, 394-398.

[19] Mitchell, R., Myles, F., \& Marsden, E. J. (2013). Second Language Learning Theories: third edition. (3rd ed.) Abingdon: Routledge.

[20] Pirtle, S. S., \&Tobia, E. (2014).Implementing effective professional learning communities. SEDL Insights, 2(3), 2-3.

[21] Pring, R. (2000). Philosophy of educational research. London: Continuum.

[22] Punch, K.F. (2009). Introduction to research methods in education. London: Sage Publications.

[23] Rabiee, F. (2004). Focus-group interview and data analysis. Proceedings of the nutrition society, 63(04), 655-660.

[24] Razi, N., \& Kargar, A. A. (2014). Evaluation of in-service foreign language teacher education program in Iran. International Journal of Language Learning and Applied Linguistics World, 5(1), 221-236.

[25] Roberts, S. M., \& Pruitt, E. Z. (Eds.). (2008). Schools as professional learning communities: Collaborative activities and strategies for professional development. Thousand Oaks California: Corwin Press.

[26] Senge, P. M. (1990). The art and practice of the learning organization (pp. 3-11). New York: Doubleday.

[27] Shirazi, Z. R. H., Bagheri, M. S., Sadighi, F., \&Yarmohammadi, L. (2013).Rethinking professional development in Iran. Middle-East Journal of Scientific Research, 16(1), 108-113.

[28] Skaalvik, E. M., \& Skaalvik, S. (2011). Teacher job satisfaction and motivation to leave the teaching profession: Relations with school context, feeling of belonging, and emotional exhaustion. Teaching and teacher education, 27(6), 1029-1038.

[29] Stoll, L., \& Louis, K. S. (2007). Professional learning communities: Divergence, depth and dilemmas. McGraw-Hill Education (UK).

[30] Stoll, L., Bolam, R., McMahon, A., Wallace, M., \& Thomas, S. (2006). Professional learning communities: A review of the literature. Journal of educational change, 7(4), 221-258.

[31] Talbert, J. E. (2010). Professional learning communities at the crossroads: How systems hinder or engender change. In Second international handbook of educational change, 555-571. Springer Science \& Business Media.

[32] Tschannen-Moran, M. (2014). Trust matters: Leadership for successful schools (2nd ed.). San Francisco: Jossey-Bass.

[33] Vescio, V., Ross, D., \& Adams, A. (2008). A review of research on the impact of professional learning communities on teaching practice and student learning. Teaching and teacher education, 24(1), 80-91.

[34] Wood, D. R. (2007). Professional learning communities: Teachers, knowledge, and knowing. Theory into Practice, 46(4), 281290.

Nazanin Dehdary is an EdD candidate at the University of Exeter. She taught English in Iran for 16 years and joined CPS at Sultan Qaboos University, Oman in 2015. Her research interests focus on curriculum development, teacher training, and critical pedagogy. 